\title{
Extração de ecdisterona em raízes de ginseng brasileiro
}

\author{
Extraction of ecdysterone from roots of Brazilian ginseng
}

\section{Rejane Flores $^{\mathrm{I}}$ Fernando Teixeira Nicoloso $^{\mathrm{II}}$ Daniela BrondaniIII Joseila Maldaner Verciane Cezarotto $^{\text {IV }}$ Sandro Rogério Giacomelliv}

\begin{abstract}
- NOTA -
RESUMO

Este estudo teve como objetivo otimizar a extração de ecdisterona em raízes de ginseng brasileiro. Primeiramente, para se avaliar a eficiência do solvente extrator, amostras de raízes dois acessos (BRA e JB-UFSM) de P. glomerata foram extraídas em Soxhlet com metanol e clorofórmio, separadamente, durante 4 horas. No segundo ensaio, com o intuito de se escolher o método extrator, a extração foi conduzida

samples were extracted with methanol in a Soxhlet or in ultrasonic. The ecdysterone content was determinated using high efficiency liquid chromatography methods. In both studied species, the highest ecdisterone content was detected from samples extracted in a Soxhlet and using methanol as a solvent. This extration method has been successfully applied for determination of ecdysterone content from roots of Brazilian ginseng, and could be useful for the quality control of drugs and pharmaceutical formulations.
\end{abstract} em Soxhlet e em ultrassom, utilizando metanol como solvente. Em P. tuberosa, as amostras foram extraídas com metanol, e a extração foi conduzida em Soxhlet e em banho ultrasônico. $O$ conteúdo de ecdisterona foi determinado em Cromatógrafo Líquido de Alta Eficiência (CLAE). Em ambas as espécies, um maior conteúdo de ecdisterona foi detectado nas amostras extraídas com metanol e em Soxhlet. A metodologia proposta mostrou-se eficaz para a quantificação da ecdisterona a partir das raízes de $\boldsymbol{P}$. glomerata e $\boldsymbol{P}$. tuberosa, podendo ser aplicada no controle de qualidade de drogas vegetais e/ou fitoterápicos.

Palavras-chave: Pfaffia glomerata, Pfaffia tuberosa, ecdisteróides, fitoterápico, controle de qualidade

\section{ABSTRACT}

This study aimed at optimizing the extraction method from ecdysterone of Brazilian ginseng. Root samples of two accessions (BRA and JB-UFSM) of P. glomerata were extracted in a Soxhlet with methanol or chloroform for $4 \mathrm{~h}$. In the second trial, the extration was conduced in a Soxhlet or ultrasonic using metanol as a solvent. In P. tuberosa, the roots
Key words: Pfaffia glomerata, Pfaffia tuberosa, ecdysteroids, phytomedicine, quality control

Pfaffia glomerata, conhecida como ginseng brasileiro, apresenta grande importância medicinal e comercial, devido a suas raízes apresentarem efeitos adaptógenos, tônicos e afrodisíacos. Esses efeitos estão relacionados à presença de saponinas triterpênicas e ecdisteróides, compostos isolados a partir das raízes das plantas, as quais são utilizadas pela indústria farmacêutica para a produção de fitoterápicos e suplementos alimentares (MAGALHAES, 2000). Pfaffia tuberosa é uma espécie nativa dos campos de vários Estados do Brasil e países vizinhos, cujas propriedades químicas e farmacológicas foram até o momento pouco investigadas (NISHIMOTO et al., 1986).

\footnotetext{
'Programa de Pós-graduação em Agronomia, Universidade Federal de Santa Maria (UFSM), Santa Maria, RS, Brasil.

IIDepartamento de Biologia, UFSM, Campus Universitário, Camobi, 97105-900, Santa Maria, RS, Brasil. E-mail: ftnicoloso@yahoo.com. Autor para correspondência.

${ }^{\text {IIIC } C u r s o ~ d e ~ Q u i ́ m i c a ~ I n d u s t r i a l, ~ U n i v e r s i d a d e ~ R e g i o n a l ~ I n t e g r a d a ~(U R I), ~ F r e d e r i c o ~ W e s t p h a l e n, ~ R S, ~ B r a s i l . ~}$

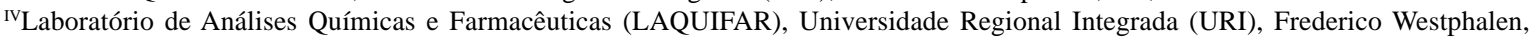
RS, Brasil.

vDepartamento de Química, URI, Frederico Westphalen, RS, Brasil.
} 
Dentre os parâmetros utilizados na avaliação da qualidade da matéria-prima de $\boldsymbol{P}$. glomerata, destacase a análise quantitativa de ecdisterona utilizando o Cromatógrafo Líquido de Alta Eficiência (CLAE) (BRASIL, 2004). Nesse sentido, faz-se necessário o desenvolvimento de uma metodologia simples, rápida e eficiente para a extração desse metabólito nas raízes da planta. Assim, tendo em vista os critérios de qualidade exigidos para a matéria-prima e para os medicamentos fitoterápicos junto à Agência Nacional de Vigilância Sanitária (BRASIL, 2004), o objetivo deste estudo foi otimizar a extração de ecdisterona a partir de raízes de $\boldsymbol{P}$.glomerata e $\boldsymbol{P}$. tuberosa.

Plantas dos acessos BRA e JB-UFSM de $\boldsymbol{P}$. glomerata (SMDB 7606) foram micropropagadas (NICOLOSO et al., 2001) e plantadas no Município de São Pedro do Sul, Rio Grande do Sul (RS). Dois anos após o plantio no solo, as plantas foram coletadas e submetidas à extração e quantificação da ecdisterona. As plantas de $\boldsymbol{P}$. tuberosa (SMDB 9840) utilizadas neste estudo foram oriundas de populações naturais existentes no Município de São Pedro do Sul, RS.

As raízes de $\boldsymbol{P}$. tuberosa e $\boldsymbol{P}$. glomerata foram secadas em estufa $\left(50^{\circ} \mathrm{C}\right)$ e trituradas. Primeiramente, foi avaliado o efeito dos solventes metanol (MAGALHÃES, 2000) e clorofórmio (FREITAS et al., 2004), separadamente, na extração da ecdisterona, nas raízes dos dois acessos de P. glomerata. As amostras $(1,0 \mathrm{~g})$ foram submetidas à extração com $125 \mathrm{~mL}$ de metanol (grau CLAE, Vetec) e com clorofórmio (Vetec), separadamente, em Soxhlet, durante 4 horas. Os extratos metanólicos foram concentrados $(100 \mathrm{~mL})$, e os extratos obtidos com clorofórmio foram submetidos à evaporação total do solvente em evaporador rotatório, sendo o extrato obtido ressuspendido com metanol, grau CLAE. Ambos os extratos foram filtrados $(0,45 \mu \mathrm{m}$, Millipore) antes de serem injetados no cromatógrafo.

Posteriormente, as raízes de ambos os acessos de $\boldsymbol{P}$. glomerata, bem como de $\boldsymbol{P}$. tuberosa, foram submetidas a dois diferentes métodos de extração (ultrassom e Soxhlet), utilizando o metanol como solvente (melhor resultado obtido no ensaio anterior). As amostras (200mg) foram extraídas com metanol, grau CLAE (2 vezes, $5 \mathrm{~mL}$ cada), em ultrassom, durante 20 minutos. O sobrenadante foi removido após centrifugação (1500rpm, 10min), e os extratos obtidos das duas extrações foram combinados (10mL). Posteriormente, as soluções foram filtradas $(0,45 \mu \mathrm{m}$, Millipore) e injetadas no cromatógrafo. O procedimento de extração em Soxhlet foi conduzido conforme a metodologia adaptada de MAGALHÃES (2000) descrita anteriormente.

As análises foram realizadas no CLAE, com detector UV-Vis e coluna analítica Spheri 5, C-18 (PerkinElmer, 220 x 4,6mm, partículas de $5 \mu \mathrm{m}$ ). A fase móvel consistiu de metanol (100\%), grau CLAE, utilizando fluxo constante de $1 \mathrm{~mL} \mathrm{~min}{ }^{-1}$. A detecção dos picos ocorreu em $245 \mathrm{~nm}$. A quantificação da ecdisterona foi feita por meio do método do padrão externo, sendo a curva analítica construída com padrão autêntico (ChromaDex Inc.). A ecdisterona apresentou Tempo de Retenção (Rt) de 2,7min. Os resultados representaram a média de triplicatas. O teor de ecdisterona foi determinado em relação a $100 \mathrm{~g}$ de massa seca (\%). Os dados foram submetidos à análise da variância e analisados pelo teste de Duncan, em nível de 1\% de probabilidade de erro.

A análise das amostras por CLAE mostrou que o conteúdo de ecdisterona detectado nas raízes de $\boldsymbol{P}$ glomerata diferiu estatisticamente em relação ao solvente utilizado na fase de extração. Em ambos os acessos de $\boldsymbol{P}$.glomerata, um maior teor de ecdisterona foi extraído utilizando-se o solvente metanol quando comparado ao clorofórmio (Tabela 1). Além disso, quando o metanol foi utilizado como solvente, observou-se que os acessos de $\boldsymbol{P}$. glomerata diferiram entre si em relação ao teor de ecdisterona presente nas raízes, e o acesso BRA apresentou uma maior quantidade do metabólito $(0,43 \%)$ em relação ao JB$\operatorname{UFSM}(0,28 \%)$ (Tabela 1$)$.

Tabela 1 - Efeito do solvente extrator e método de extração no teor de ecdisterona (\% por massa seca), nas raízes de plantas dos acessos BRA e JB-UFSM de Pfaffia glomerata.

\begin{tabular}{llcr}
\hline \multirow{2}{*}{ Extração } & & BRA & JB-UFSM \\
\hline \multirow{2}{*}{ Solvente } & metanol & $0,43 \pm 0,006 \mathrm{aA}^{*}$ & $0,28 \pm 0,006 \mathrm{aB} *$ \\
\multirow{2}{*}{ Método } & clorofórmio & $0,04 \pm 0,007 \mathrm{bA}$ & $0,01 \pm 0,005 \mathrm{bA}$ \\
& soxhlet & $0,42 \pm 0,006 \mathrm{aA} * *$ & $0,28 \pm 0,006 \mathrm{aB} * *$ \\
\hline
\end{tabular}

*Médias seguidas de mesma letra minúscula não diferem quanto ao tipo de solvente e maiúsculas quanto ao acesso, pelo Teste de Duncan, em nível de $1 \%$ de probabilidade de erro.

**Médias seguidas de mesma letra minúscula não diferem quanto ao método de extração e maiúsculas quanto ao acesso, pelo Teste de Duncan, em nível de 1\% de probabilidade de erro. 
Um baixo teor de ecdisterona foi detectado nas amostras extraídas com clorofórmio, não sendo observada diferença estatística entre os acessos (Tabela 1). Em geral, durante os procedimentos de extração de metabólitos a partir de plantas, deve-se dar preferência aos solventes mais seletivos (FALKENBERG et al., 2002). No presente estudo, a comparação entre os cromatogramas mostrou que o metanol (Figura 1A e 1B) foi mais seletivo para a ecdisterona em relação ao clorofórmio, na região de 245nm, sendo visualizadas várias substâncias interferentes (Figura 1C e 1D). Além disso, utilizando o metanol, os acessos estudados não apresentaram diferenças em relação ao número e tempo de retenção dos picos cromatográficos (Figura 1A e 1B). Entretanto, nas amostras extraídas com o clorofórmio, no acesso BRA, a ecdisterona foi detectada em concentração superior aos demais compostos presentes na amostra (Figura 1C), enquanto que, no acesso JB-UFSM, outro composto com Tempo de Retenção de 3,35min apresentou pico superior a ecdisterona (Figura 1D). Dessa forma, o clorofórmio poderá ser um solvente útil para a extração de outros compostos químicos presentes nas raízes de $\boldsymbol{P}$. glomerata, além da ecdisterona.

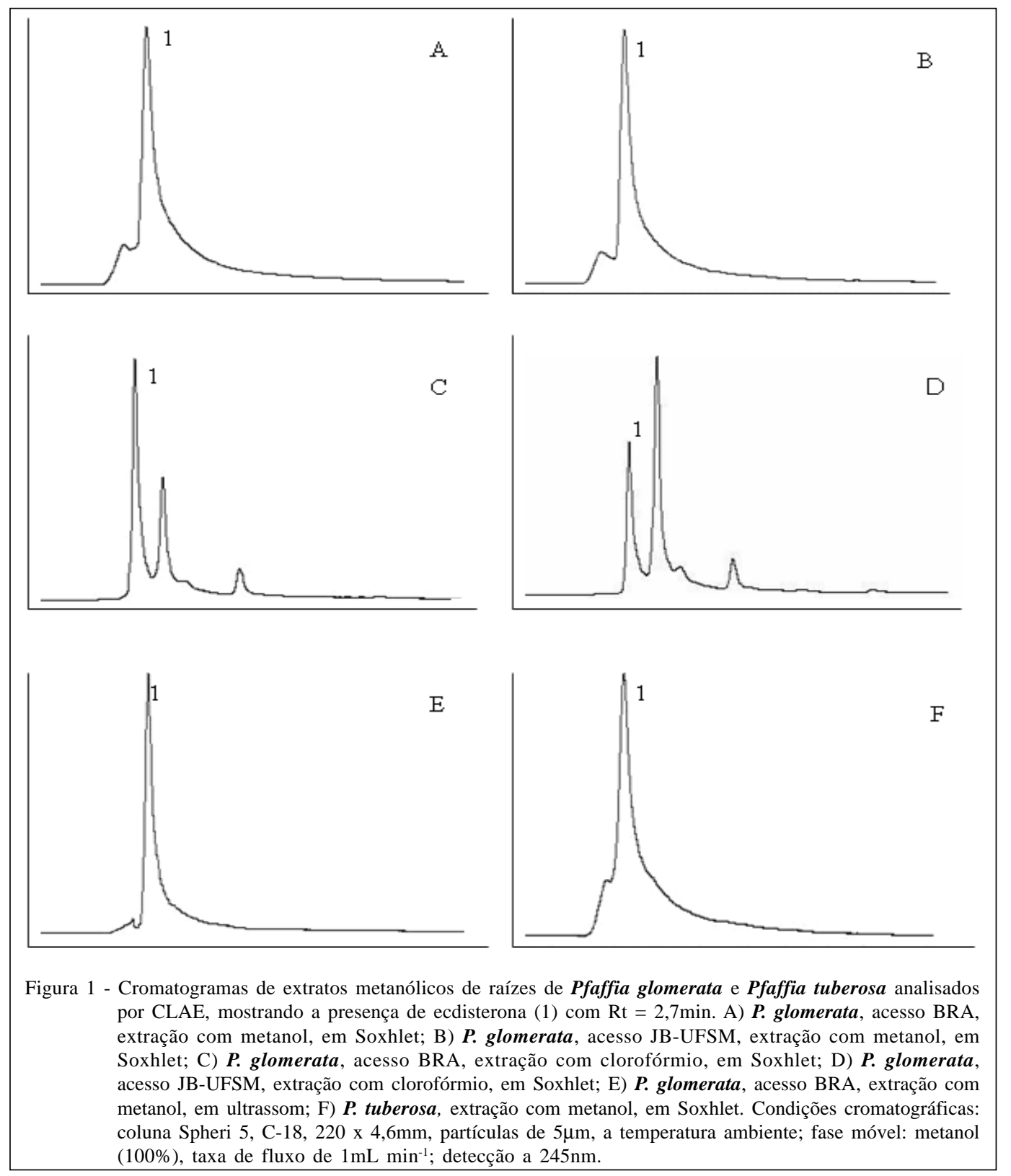

Ciência Rural, v.39, n.4, jul, 2009. 
Em ambos os acessos de $\boldsymbol{P}$. glomerata, o conteúdo de ecdisterona diferiu dependendo do método de extração utilizado. O uso do Soxhlet foi mais efetivo em relação ao ultrassom (Tabela 1). Semelhante ao observado anteriormente, utilizando a extração em Soxhlet, os acessos diferiram em relação ao conteúdo de ecdisterona (Tabela 1). Por outro lado, quando a extração foi conduzida no ultrassom, o teor de ecdisterona não diferiu estatisticamente entre os acessos (Tabela 1). O cromatograma da ecdisterona obtido com metanol e em banho ultrassônico, a partir as raízes do acesso BRA, pode ser observado na Figura $1 \mathrm{E}$.

Da mesma forma, em $\boldsymbol{P}$. tuberosa, uma quantidade significativamente maior de ecdisterona foi extraída com o Soxhlet $(0,14 \pm 0,006 \%)$ (Figura $1 F)$, em relação ao ultrassom $(0,02 \pm 0,006 \%)$. Apesar de, neste estudo, extração em Soxhlet ter sido superior ao uso do banho ultrassônico, este tipo de extração vem sendo muito utilizado na análise de amostras in vitro (TOMÁS et al., 1993).

A metodologia desenvolvida viabilizou a quantificação de ecdisterona a partir das raízes de $\boldsymbol{P}$. glomerata e $\boldsymbol{P}$. tuberosa. As amostras extraídas, com metanol, em Soxhlet (Figura 1A, 1B, 1F), apresentaram um alto teor de ecdisterona em relação aos demais compostos detectados e a um pequeno número de interferentes em relação à extração com clorofórmio (Figura 1C, 1D) e em ultrassom. Além disso, o uso do metanol grau CLAE na extração tornou o método mais simples e rápido quando comparado com as metodologias de MAGALHÃES (2000) e FREITAS et al. (2004), nas quais o solvente necessita ser evaporado antes da adição do metanol grau CLAE. Esse aspecto é importante, pois permite uma maior rapidez nas análises da matéria-prima e/ou fitoterápicos produzidos com o ginseng brasileiro. Os resultados referentes à extração em ultrassom são pioneiros para a Pfaffia e poderão ser utilizados, alternativamente, para a detecção e/ou quantificação rápida de ecdisterona, principalmente quando se dispõe de uma pequena quantidade de amostra.

Os resultados permitiram concluir que a metodologia de extração em Soxhlet e a utilização de metanol como solvente foram eficazes para a quantificação da ecdisterona a partir das raízes de $\boldsymbol{P}$. glomerata e $\boldsymbol{P}$. tuberosa, podendo ser aplicadas no controle de qualidade das drogas vegetais e/ou fitoterápicos.

\section{REFERÊNCIAS}

BRASIL. Ministério da Saúde. Agência Nacional de Vigilância Sanitária (ANVISA). Resolução RDC no 48 de 16 de março de 2004. Dispõe sobre o registro de medicamentos fitoterápicos. Ministério da Saúde, Brasil, 2004. Diário Oficial da União, 18 mar. 2004. p.15-16.

FALKENBERG, M.B. et al. Introdução à análise fitoquímica. In: SIMÕES, M.O. et al. Farmacognosia: da planta ao medicamento. 4.ed. Porto Alegre/Florianópolis: UFRGS/ UFSC, 2002. p.165-181.

FREITAS, C.S. et al. Involvement of nitric oxide in the gastroprotective effects of an aqueous extract of Pfaffia glomerata (Spreng.) Pedersen, Amaranthaceae, in rats. Life Sciences, Oxford, v.74, p.1167-1179, 2004.

MAGALHÃES, P.M. de. Agrotecnologia para el cultivo de fáfia o ginseng brasileiro. In: MARTINEZ, J.V. et al. Fundamentos de agrotecnología de cultivo de plantas medicinales iberoamericanas. Santafé de Bogotá: Convênio Andrés Bello/CYTED, 2000. p.323-332.

NICOLOSO, F.T. et al. Micropropagação do Ginseng brasileiro (Pfaffia glomerata (Spreng.) Pedersen). Revista Brasileira de Plantas Medicinais, Botucatu, v.3, p.11-18, 2001.

NISHIMOTO, N. et al. Ecdysterone from Pfaffia tuberosa (Spreng,) Hicken. Revista Brasileira de Farmacognosia, Maringá, v.1, n.2, p.188-191, 1986.

TOMÁS, J. et al. Phytoecdisteroid production by Ajuga reptans tissue culture. Phytochemistry, Oxford, v.32, n.2, p.317324, 1993. 